\title{
An unusual cause of rapid atrial fibrillation
}

\author{
Antoine Lamblin, MD · Jean Turc, MD • Pierre-François Wey, MD • \\ Olivier Eve, MD • Michel Bérend, MD · Fabrice Petitjeans, MD • \\ Pascal Précloux, MD
}

Received: 12 October 2012/Accepted: 25 January 2013/Published online: 16 February 2013

(C) Canadian Anesthesiologists' Society 2013

\begin{abstract}
A 75-yr-old man who presented with stenotic lower-third esophageal cancer was anesthetized for iterative palliative endoscopic dilatation. In the operating room, a case of welltolerated new onset rapid atrial fibrillation (AF) (170 beats $\min ^{-1}$ ) was diagnosed. This diagnosis prompted us to postpone the procedure. In the morning, an electrocardiogram revealed the absence of cardiac rhythm abnormalities; however, fluid expansion and intravenous administration of magnesium sulfate $1.5 \mathrm{~g}$ proved ineffective. In the recovery room, the anesthesiologist performed a transthoracic echocardiogram (TTE) that revealed an extrinsic compression of
\end{abstract}

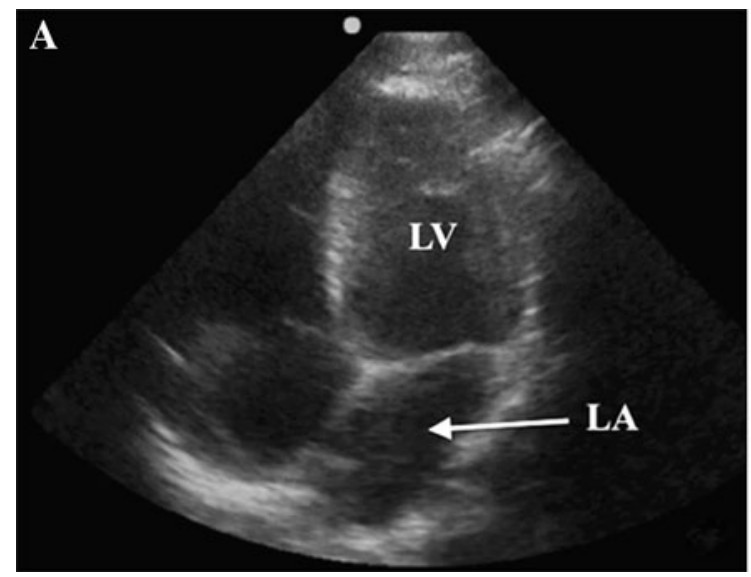

Fig. 1 Panel A Normal transthoracic echocardiogram showing a four-chamber view; left atrial (LA), left ventricular (LV); panel $B$ : Transthoracic echocardiogram showing a four-chamber view with LA

A. Lamblin, MD (ه) · J. Turc, MD · P.-F. Wey, MD .

O. Eve, MD · M. Bérend, MD · F. Petitjeans, MD ·

P. Précloux, MD

Hôpital d'Instruction des Armées (HIA) Desgenettes, Lyon,

France

e-mail: antoine.lamblin@hotmail.fr the posterior left atrial wall by a circular hyperechogenic structure (Fig. 1, panel B). A computed tomography scan confirmed that the structure was an esophageal stent that had been invaded by the tumour (Fig. 2). The left ventricular ejection fraction was approximately $50 \%$, which allowed the physicians to attempt cardioversion by intravenous administration of amiodarone $300 \mathrm{mg}$. The patient's heart rate normalized within one hour, and general anesthesia was then performed.

New onset AF with poor tolerance or uncontrolled heart rate in the preoperative setting is a rare condition, and

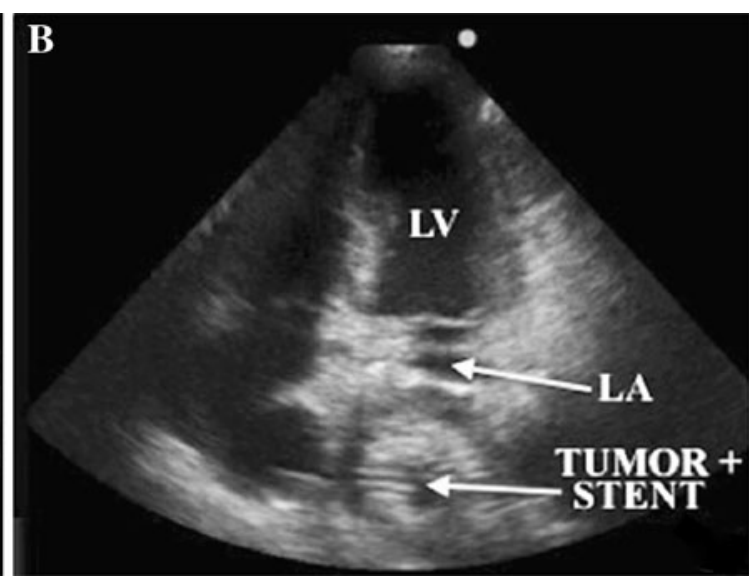

extrinsic compression by an esophageal stent that has been invaded by the esophageal tumour (tumour + stent) 


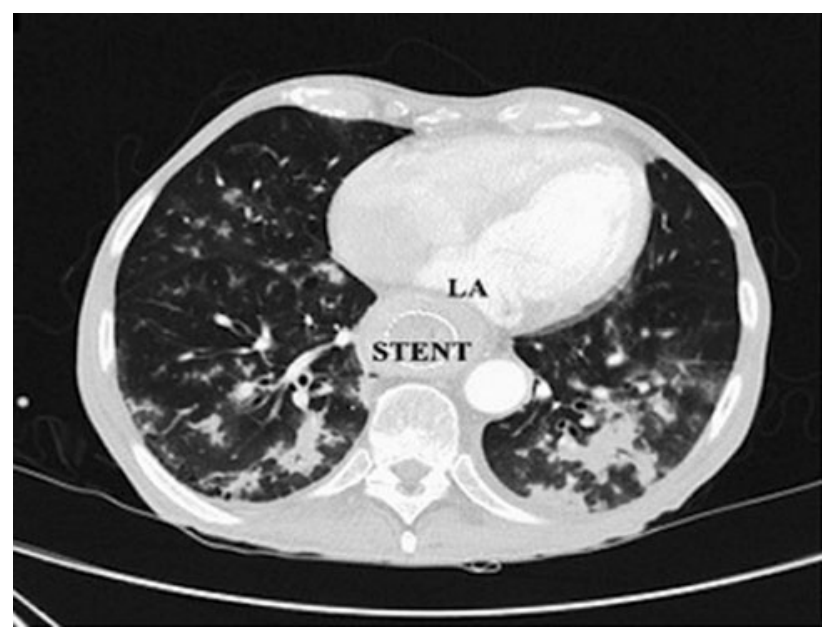

delay of surgery should be considered until further cardiovascular evaluations are performed. The TTE should be performed to diagnose valvular pathologies, systolic or diastolic dysfunction, chamber size, pericardial effusion or tamponade, and the involvement or compression of the pulmonary veins, which can lead to AF. Our case report emphasizes the importance of global evaluation of patients in the operating room as well as the prompt availability of polyvalent sonography, not only for ultrasound-guided procedures but also for cardiovascular assessments of appropriate patients.

Competing interests None declared.

Fig. 2 Thoracic computed tomography scan (axial view) showing left atrial (LA) compression by the esophageal stent (STENT) that has been invaded by the esophageal tumour 